\title{
The utility of apoptosis inhibitor of macrophages as a possible diagnostic marker in patients with Crohn's disease
}

\author{
Yohei Ono ${ }^{1}$, Shuji Kanmura ${ }^{1}$, Yuko Morinaga ${ }^{1}$, Kohei Oda ${ }^{1}$, Katsuto Kawabata' ${ }^{1}$, Shiho Arima ${ }^{1}$, Fumisato Sasaki ${ }^{1}$, \\ Yuichirou Nasu', Shiroh Tanoue ${ }^{1}$, Shinichi Hashimoto ${ }^{1}$, Hiroki Taguchi ${ }^{1}$, Hirofumi Uto ${ }^{1,2}$, Hirohito Tsubouchi ${ }^{3}$ \\ and Akio Ido ${ }^{1}$
}

\begin{abstract}
Background: Apoptosis inhibitor of macrophages (AIM) was initially identified as an apoptosis inhibitor that supports the survival of macrophages against various apoptosis-inducing stimuli, and AIM produced by macrophages may contribute to the pathogenesis of inflammatory bowel diseases (IBDs). However, there have been no reports on the kinetics of AIM in IBD and the impact of AIM on the pathogenesis of IBD. In this study, we aimed to investigate the diagnostic utility of levels of AIM and their correlation with the activity of Crohn's disease (CD) and IBD.
\end{abstract}

Methods: We used an enzyme-linked immunosorbent assay (ELISA) to examine AIM serum levels in 16 healthy subjects and 90 patients with inflammatory bowel diseases, namely 39 with CD and 51 with ulcerative colitis (UC), as well as 17 patients with Behcet's disease (BD) as intestinal disease controls. We compared serum AIM levels among groups and examined whether there were correlations between serum AIM levels and disease activity and type. We also performed immunohistochemical staining of AIM in intestinal tissues of patients with CD.

Results: Serum AIM levels were significantly higher in patients with CD than in patients with UC, BD, and controls (3.27 \pm $2.14,1.88 \pm 1.43,2.34 \pm 1.37$, and $2.13 \pm 0.64 \mu \mathrm{g} / \mathrm{ml}$, respectively; $P<0.01)$. There was no difference in serum AlM levels before and after treatment in patients with CD. However, in these patients the diagnostic rate using AIM was better than that based on anti-Saccharomyces cerevisiae antibodies. AlM was expressed in macrophages that were positive for CD14, CD16, or both in the intestinal tissues of patients with CD.

Conclusions: AIM is a novel biomarker of CD that can distinguish CD from UC or BD. It is suggested that AIM may contribute to intestinal inflammation by inhibiting the apoptosis of macrophages.

Keywords: Inflammatory bowel diseases, Crohn's disease, Macrophages, Apoptosis inhibitor of macrophages

\section{Background}

Inflammatory bowel diseases (IBDs), including Crohn's disease (CD) and ulcerative colitis (UC), are chronic intestinal disorders of unclear etiology [1]. The incidence of both conditions is increasing globally, and it is suggested that disease risk correlates with environmental changes [2]. Although the etiology of IBD remains unknown, it is thought to be strongly associated with the microbiome and the

\footnotetext{
* Correspondence: skanmura@m2.kufm.kagoshima-u.ac.jp

${ }^{1}$ Digestive and Lifestyle Diseases, Kagoshima University Graduate School of Medical and Dental Sciences, 8-35-1, Sakuragaoka, Kagoshima 890-8520, Japan

Full list of author information is available at the end of the article
}

environmental factors that influence the microbiome [3]. Intestinal macrophages influence local homeostasis and help maintain a balance between commensal microbiota and the host. Additionally, intestinal macrophages play essential roles in intestinal inflammation. As a result, disorders of intestinal macrophages may cause unbalanced immune responses to commensal bacteria and lead to the development of chronic intestinal inflammation [4]. These macrophages play an important role in the pathogenesis of IBDs such as CD [5, 6].

The diagnosis of IBD is based on endoscopic, histologic and radiologic criteria. Disease activity in IBD is determined using both direct and non-invasive laboratory markers. 
However, endoscopy is still the gold standard diagnostic test, even though it is invasive [7, 8]. Several serological markers, such as C-reactive protein (CRP), as well as erythrocyte sedimentation rate (ESR) and platelet count or fecal calprotectin have been reported to be useful for diagnosing IBD and assessing disease activity and response to therapy [9-15]. An ideal marker for IBD would have high disease specificity, predictive ability for relapse of disease activity, and is cheap and noninvasive [16]. Currently, several serologic markers have been suggested as useful for the diagnosis, differentiation, and better comprehension of the pathogenesis of IBD [17-20]. Among them, anti-Saccharomyces cerevisiae antibodies (ASCA) and perinuclear antineutrophil cytoplasmic antibodies have been reported to be useful serum biomarkers for $\mathrm{CD}$ and $\mathrm{UC}$, respectively [21]. ASCA has a low positivity rate of between 38.3 and $45.6 \%$

Table 1 Clinical characteristics

\begin{tabular}{|c|c|c|c|c|c|}
\hline & $C D$ & UC & $B D$ & Control & $P$ value \\
\hline Number of patients & 39 & 51 & 17 & 16 & \\
\hline \multicolumn{6}{|l|}{ Gender } \\
\hline Male & 20 & 27 & 9 & 14 & 0.070 \\
\hline Female & 19 & 24 & 8 & 2 & \\
\hline Mean age $( \pm S D)$, yr & $32.4 \pm 14.5$ & $45.2 \pm 22.8$ & $47.5 \pm 17.6$ & $32.4 \pm 3.8$ & 0.014 \\
\hline BMI $( \pm S D), k g / m^{2}$ & $19.0 \pm 3.6$ & $21.6 \pm 3.7$ & $20.4 \pm 3.8$ & & 0.006 \\
\hline \multicolumn{6}{|l|}{ CDAl } \\
\hline$\geq 150$ & 12 & & & & \\
\hline$<150$ & 27 & & & & \\
\hline \multicolumn{6}{|l|}{ CAl } \\
\hline$\geq 6$ & & 29 & & & \\
\hline$<6$ & & 22 & & & \\
\hline \multicolumn{6}{|l|}{ Disease location } \\
\hline \multicolumn{6}{|l|}{$C D$} \\
\hline Ileal type & 9 & & & & \\
\hline Ileocolonic type & 25 & & & & \\
\hline Colonic type & 4 & & & & \\
\hline Unknown & 1 & & & & \\
\hline \multicolumn{6}{|l|}{ UC } \\
\hline Pancolitis & & 41 & & & \\
\hline Left side colon & & 4 & & & \\
\hline Rectum & & 5 & & & \\
\hline Unknown & & 1 & & & \\
\hline \multicolumn{6}{|l|}{ Current treatment } \\
\hline 5-ASA & 25 & 43 & 13 & & \\
\hline Steroid & 2 & 18 & 6 & & \\
\hline Azathioprine & 0 & 5 & 0 & & \\
\hline Infliximab & 5 & 0 & 0 & & \\
\hline Adalimumab & 1 & 0 & 0 & & \\
\hline GMA/LCAP & 1 & 6 & 1 & & \\
\hline \multicolumn{6}{|l|}{ AlM $(\mu \mathrm{g} / \mathrm{ml})$} \\
\hline Average $( \pm S D)$ & $3.3 \pm 2.1$ & $1.9 \pm 1.4$ & $2.3 \pm 1.4$ & $2.1 \pm 0.6$ & $<0.001$ \\
\hline $\mathrm{WBC}( \pm \mathrm{SD}), \times 10^{2} / \mu \mathrm{l}$ & $6.7 \pm 2.6$ & $8.4 \pm 3.9$ & $7.3 \pm 2.8$ & - & 0.055 \\
\hline $\mathrm{CRP}( \pm \mathrm{SD}), \mathrm{mg} / \mathrm{dl}$ & $2.5 \pm 3.5$ & $3.6 \pm 5.8$ & $2.7 \pm 4.0$ & - & 0.929 \\
\hline $\operatorname{lgM}( \pm S D), \mathrm{mg} / \mathrm{dl}$ & $141.5 \pm 124.3$ & $118.0 \pm 77.9$ & $118.0 \pm 64.9$ & - & 0.275 \\
\hline
\end{tabular}

Abbreviations: GMA/LCAP granulocyte and monocyte adsorptive apheresis / leukocytapheresis, WBC White blood cell, CRP C-reactive protein, IgM Immunoglobulin $\mathrm{M}$ 
in $\mathrm{CD}$ patients, but there is low sensitivity and specificity for the diagnosis of $\mathrm{CD}[22,23]$. A definite diagnosis is necessary for properly choosing clinical follow-up and suitable therapies. However, some IBD cases share several endoscopic and histologic features with both $\mathrm{CD}$ and UC; these are defined as indeterminate colitis [24]. Therefore there is still a need in clinical settings for IBD markers with high sensitivity and specificity.

Apoptosis inhibitor of macrophages (AIM) was initially identified as an apoptosis inhibitor that supports the survival of macrophages against various apoptosis-inducing stimuli [25]. AIM is produced exclusively by tissue macrophages and itself influences these cells [26]. Higher blood levels of AIM are associated with autoimmune disease, but only in obese individuals. Arai et al. implicated blood AIM as a biomarker for obesity-associated autoimmune disease in humans [27]. Disorders of intestinal macrophages may lead to the development of chronic intestinal inflammation, and AIM produced by the macrophage may contribute to the pathogenesis of IBDs such as CD [4-6]. However, there have been no reports on the kinetics of AIM in IBD and the impact of AIM on the pathogenesis of IBD. In this study, we aimed to investigate AIM kinetics in the blood and tissues of patients with IBD, and examined the utility of AIM as a biomarker of IBD. We then determined whether blood levels of AIM were associated with clinical features such as disease activity and type.

\section{Methods}

\section{Patients}

This study enrolled 90 IBD patients, 39 of whom were diagnosed with CD and 51 with UC (Table 1). Seventeen patients with intestinal Behcet's disease (BD) were used as intestinal disease controls. There were also 16 healthy individuals in the control group. Of the 39 patients with $\mathrm{CD}, 20$ were men and 19 were women, with a mean age of onset of 32.4 years (range, 8-79 years). Of the 51 patients with UC, 27 were men and 24 were women, with a mean age of onset of 45.2 years (range, $8-79$ years). Of the 17 patients with BD, 9 were men and 8 were women, with a mean age of onset of 47.5 years (range, 8-79 years). The mean age of healthy controls was 32.4 years (range, 8-79 years). All IBD patients were diagnosed using established endoscopic, radiological, histological, and clinical criteria. The clinical characteristics of subjects are summarized in Table 1 . Twelve patients with CD had high disease activities, defined as a Crohn's Disease Activity Index (CDAI) score of 150 or greater. Clinically, CD occurred as the ileal type in 9 patients, the ileocecal type in 25 patients, the colonic type in 4 patients, and unknown type in 1 patient. Twenty-two patients with UC were in the remission phase while 29 were in the active phase. The active phase was defined as a Lichtiger's clinical activity index (CAI) score greater than or equal to 6. All patients with BD had high disease activity based on clinical symptoms. Blood samples were collected with informed consent. The patients were treated at Kagoshima University Hospital from January 2007 to December 2013. The sera and intestinal tissue specimens of patients were stored at $-80^{\circ}$ until analysis. Excised intestinal tract tissue was stored after formalin fixation. Serum analysis was performed using the reagents and kits mentioned below. The ethics committee at Kagoshima University Hospital approved the study protocol, and written informed consent was obtained from each participant.

\section{ELISA measurements of serum AIM and ASCA levels}

We measured the serum AIM concentrations in 90 patients with IBD, 17 with BD, and 16 heathy individuals as described above. AIM levels were determined using ELISA kits from Trans Genic Inc. (Kumamoto, Japan). For comparison, we measured ASCA immunoglobulin G (IgG) in patients with CD and UC, but not those with BD. ASCA IgG concentrations were measured using ELISA kits from Genesis Diagnostics (Cambridgeshire, UK). Briefly, serum samples diluted at 1:100 were added to wells and incubated for one hour at room temperature, and then each well was washed three times with phosphate-buffered saline. Horseradish peroxidase-conjugated anti-human IgG was added to each well.

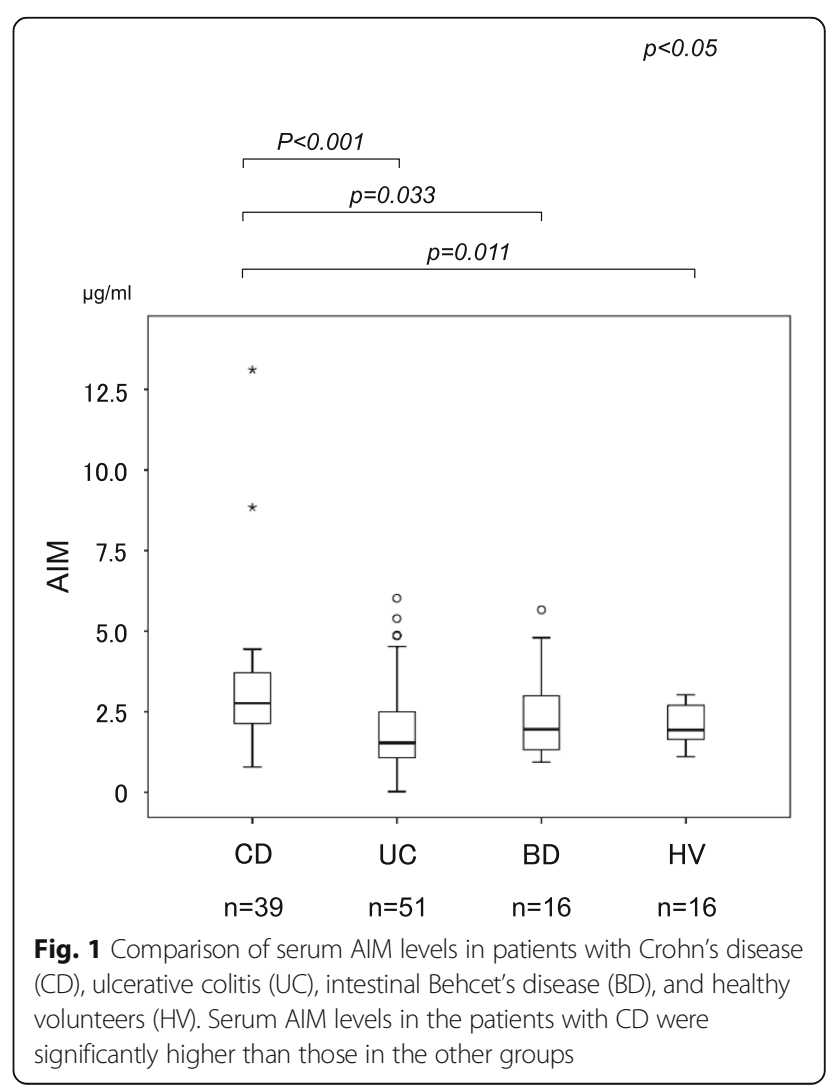




\section{Immunohistological analysis}

Small intestinal tissues from patients with active-phase CD were obtained after ileocecal resection due to intractability to medical treatment. Briefly, tissue samples were fixed with $10 \%$ buffered formalin, embedded in paraffin, and stained with hematoxylin and eosin. For immunofluorescence analysis, paraffin sections were incubated with anti-human AIM (AnaSpec, Fremont, CA, USA), anti-human CD14 (Abcam plc, Cambridge, UK), and anti-human CD16 (AbD Serotec, Oxford, UK), followed by imaging under a fluorescence microscope.

\section{Statistical analysis}

Results are expressed as means \pm standard deviation (SD). $P$ values less than 0.05 were considered statistically significant. Statistical analyses were performed using the
Chi-square or Mann-Whitney $U$ test, as appropriate. Correlation coefficients were calculated by Spearman's rank correlation analysis. The discriminatory power for each putative marker was described using the receiver operating characteristics (ROC) area under the curve (AUC) (ROC-AUC). Cut-off values were obtained from ROC-AUC analysis. Statistical analysis was conducted using PASW Statistics 18 (SPSS Inc., Chicago, IL, USA).

\section{Results}

Serum AIM levels and clinical characteristics in patients with IBD and healthy controls

The clinical characteristics of subjects are summarized in Table 1. The serum AIM concentrations in 39 patients with $\mathrm{CD}, 51$ with $\mathrm{UC}, 17$ with $\mathrm{BD}$, and 16 healthy controls were $3.27 \pm 2.14,1.88 \pm 1.43,2.34 \pm 1.37$, and

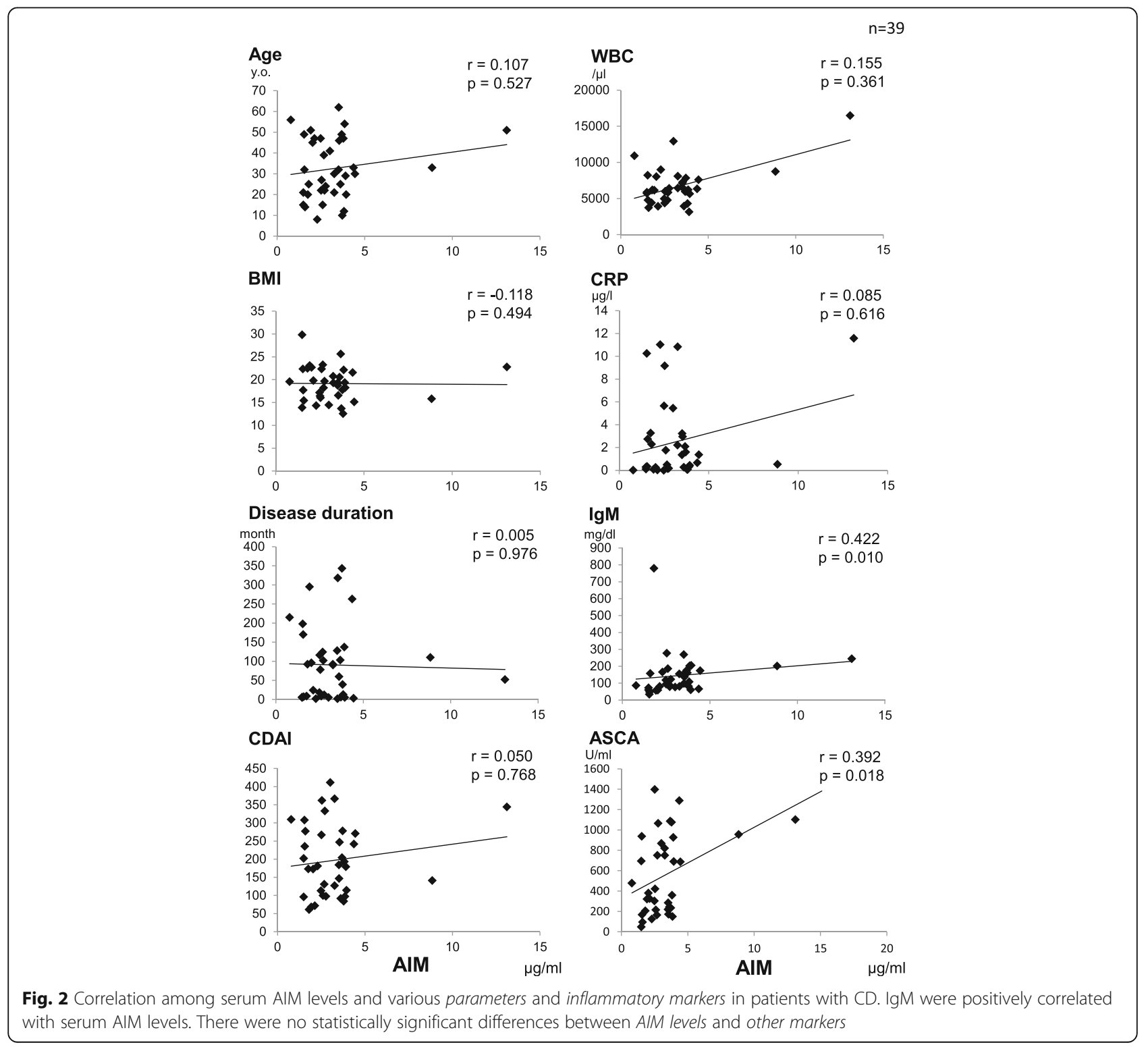


$2.13 \pm 0.64 \mu \mathrm{g} / \mathrm{ml}$, respectively (Table 1). Serum AIM levels in patients with $\mathrm{CD}$ were significantly higher than those in patients with UC and BD and those in healthy controls ( $p<0.01$ for the other groups); there was no significant difference among the latter 3 groups. Figure 1 shows the serum AIM concentration in each group. There was no significant difference between white blood cell (WBC) counts or levels of AIM, IgM, or CRP among the groups with $\mathrm{CD}, \mathrm{UC}$, and $\mathrm{BD}$.

\section{Association between serum AIM levels and other laboratory data in patients with $C D$}

We found that serum AIM levels were positively correlated with IgM in patients with CD. In contrast, no IBD patients showed significant associations between serum AIM levels and inflammatory markers such as WBC counts, CRP levels, age, disease duration, body mass index, or CDAI scores (Fig. 2). In addition, there was no

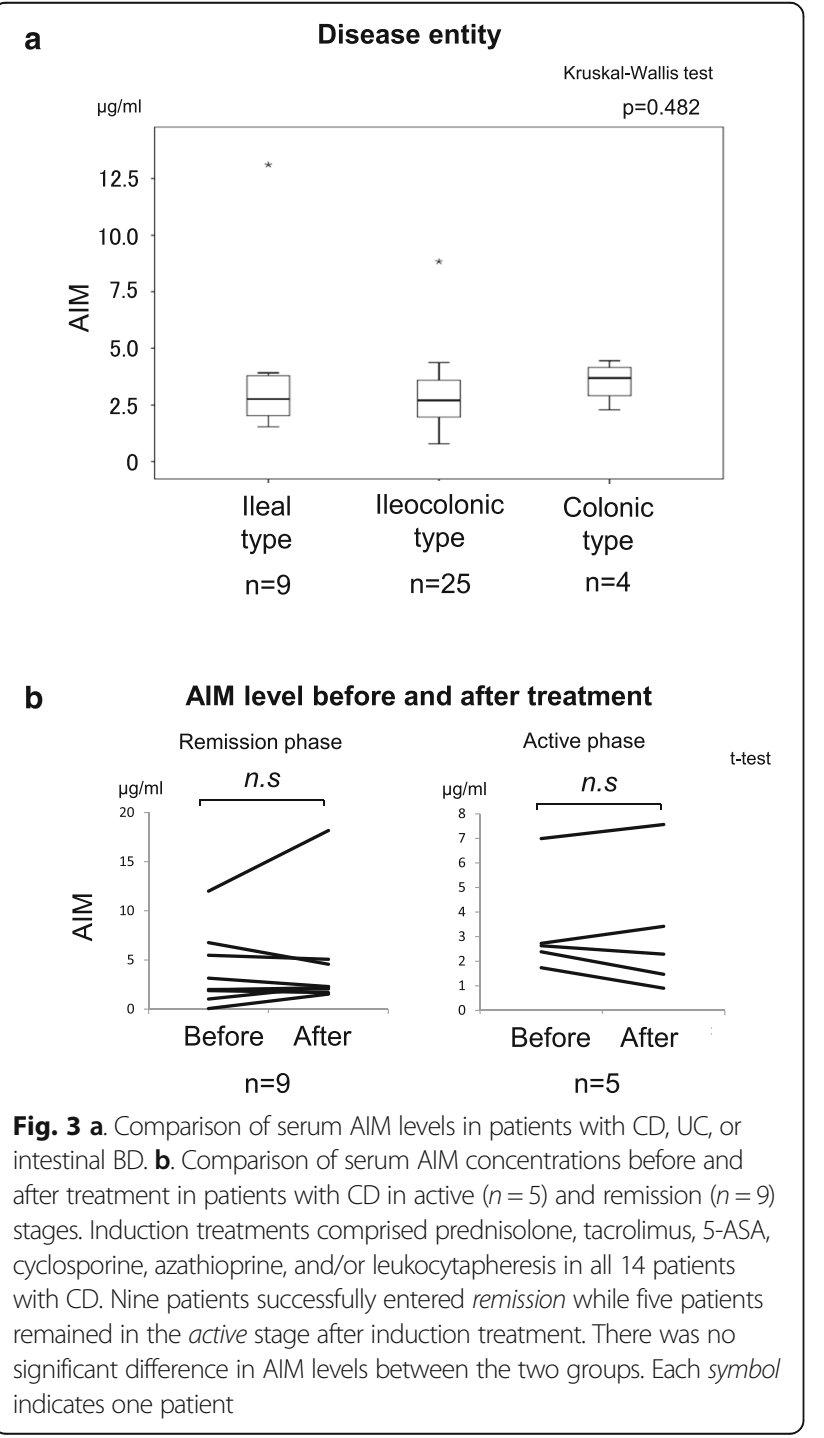

association between AIM levels and disease entities (Fig. 3). We also compared serum AIM levels before and after induction therapy in 14 patients with CD, 9 of whom had successfully entered the remission phase and 5 of whom were in the chronic active phase (Table 2). None of these patients showed an association between serum AIM levels and disease activity (Fig. 3).

\section{Diagnostic utility of serum AIM and ASCA levels in CD}

We next compared serum ASCA-IgG levels to evaluate the utility of AIM for distinguishing between CD and UC. The means \pm SD of ASCA were 955.7 $\pm 382.6,270.4 \pm 205$, and $268.5 \pm 278.3 \mathrm{U} / \mathrm{ml}$ in patients with $\mathrm{CD}$, patients with UC, and healthy controls, respectively. Serum ASCA levels in the $C D$ patients were significantly higher than those in patients with $\mathrm{UC}$ and healthy controls $(p<0.01$ for the other groups; Fig. 4).

Although, there was association between AIM levels and serum ASCA levels (Fig. 2), the ROC-AUCs of AIM and ASCA were 0.79 and 0.73 , respectively. ROC-AUC

Table 2 Clinical characteristics of CD patients in remission or active phase

\begin{tabular}{|c|c|c|c|}
\hline & Remission & Active & $P$ value \\
\hline Number of patients & 9 & 5 & \\
\hline \multicolumn{4}{|l|}{ Gender } \\
\hline Male & 3 & 2 & 0.969 \\
\hline Female & 6 & 3 & \\
\hline Mean age $( \pm S D)$, yr & $28.8 \pm 16.8$ & $24.0 \pm 8.7$ & 0.898 \\
\hline BMI $( \pm \mathrm{SD}), \mathrm{kg} / \mathrm{m}^{2}$ & $18.6 \pm 3.1$ & $20.2 \pm 6.3$ & 0.898 \\
\hline \multicolumn{4}{|l|}{ CDAl } \\
\hline$\geq 150$ & 5 & 4 & 0.658 \\
\hline$<150$ & 4 & 1 & \\
\hline \multicolumn{4}{|l|}{ Disease location } \\
\hline Ileal type & 3 & 0 & 0.167 \\
\hline Ileocolonic type & 6 & 4 & \\
\hline Colonic type & 0 & 1 & \\
\hline \multicolumn{4}{|l|}{ Induction therapy ${ }^{a}$} \\
\hline 5-ASA & 6 & 3 & \\
\hline Steroid & 1 & 0 & \\
\hline Azathioprine & 2 & 0 & \\
\hline Infliximab & 8 & 5 & \\
\hline Adalimumab & 1 & 0 & \\
\hline GMA/LCAP & 0 & 0 & \\
\hline \multicolumn{4}{|l|}{ AIM $(\mu \mathrm{g} / \mathrm{ml})$} \\
\hline \multicolumn{4}{|l|}{ Before treatment } \\
\hline Average $( \pm S D)$ & $3.8 \pm 3.7$ & $3.3 \pm 2.1$ & 0.797 \\
\hline \multicolumn{4}{|l|}{ After treatment } \\
\hline Average $( \pm S D)$ & $4.4 \pm 5.3$ & $3.1 \pm 2.7$ & 0.699 \\
\hline
\end{tabular}




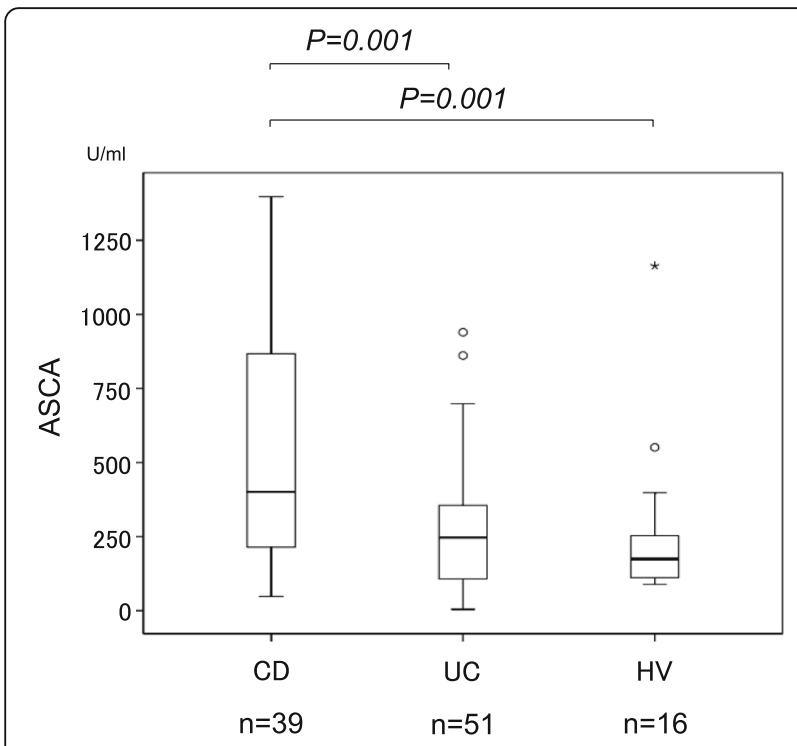

Fig. 4 Comparison of serum ASCA levels between patients with Crohn's disease (CD), ulcerative colitis (UC), and healthy volunteers $(H V)$. Serum AIM levels were significantly higher in patients with CD than in the other groups

analysis revealed that a serum AIM level of $1.88 \mu \mathrm{g} / \mathrm{ml}$ was the optimal cut-off value to differentiate between CD and UC, with $76.3 \%$ sensitivity and $76.5 \%$ specificity, a positive predictive value of $65.9 \%$, a negative predictive value of 80.6 , and $72.5 \%$ accuracy. With a cut-off value of $320 \mathrm{U} / \mathrm{ml}$, ASCA had a sensitivity of $60.5 \%$, a specificity of $72.5 \%$, a positive predictive value of $62.2 \%$, a negative predictive value of 71.1, and $67.4 \%$ accuracy (Fig. 5). Thus, the diagnostic utility of AIM is non-inferior to ASCA for the differential diagnosis of UC and CD.

\section{AIM expression in intestinal macrophages}

Histological evaluation was performed to localize AIM in tissue sections from patients with $\mathrm{CD}$ who had undergone intestinal resection due to severe intestinal inflammation. The small intestinal tissue of patients with CD showed invasion of inflammatory cells into the submucosa (hematoxylin and eosin staining). Immunostaining showed that AIM was strongly expressed in intestinal mononuclear but not epithelial cells in patients with CD (Fig. 6). Double immunostaining, performed to identify cells expressing AIM, showed that a number of AIM-positive mononuclear cells were stained by antibodies to CD14, CD16, or both, and AIM was dominantly expressed in CD16-positive cells. These results demonstrate that AIM is expressed in active macrophages located in the intestinal mucosa (Fig. 6).

\section{Discussion}

This study is the first to measure serum AIM concentrations in patients with IBD. We showed that serum AIM levels were higher in $\mathrm{CD}$ patients than in those with UC

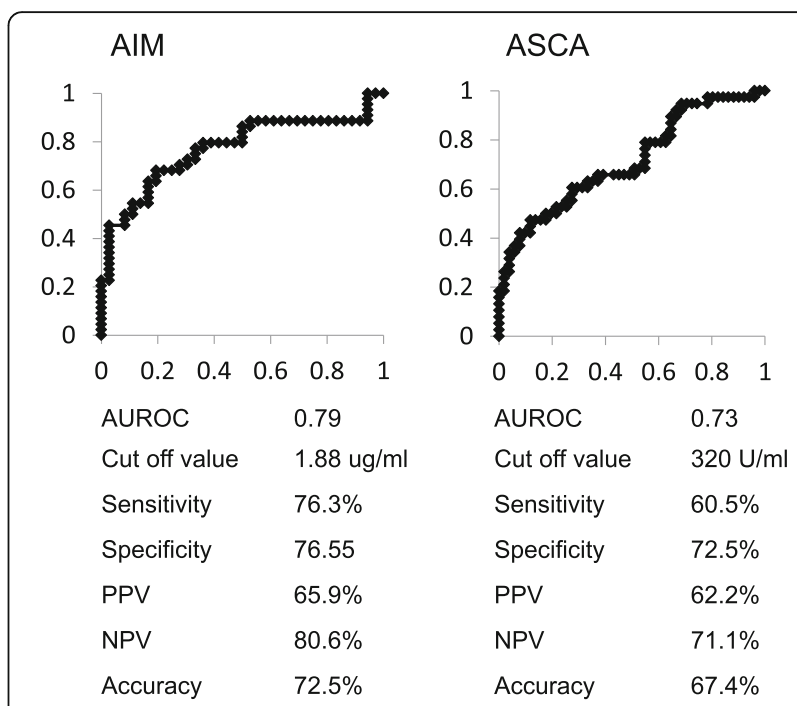

Fig. 5 Receiver operating characteristic (ROC) curves of apoptosis inhibitor of macrophage (AIM) and anti-Saccharomyces cerevisiae antibodies (ASCA) for the diagnosis of Crohn's disease (CD). The ROC curves for AIM and ASCA were obtained by plotting sensitivity versus 1-specificity. Sensitivity and specificity were each calculated using ELISA. AIM had a sensitivity of $68.2 \%$, a specificity of $80.6 \%$, a positive predictive value (PPV) of 65.9\%, a negative predictive value (NPV) of $80.6 \%$, and an accuracy of $72.5 \%$ for distinguishing CD from ulcerative colitis, while the corresponding values for ASCA were 60.5, 72.5, 62.2, 71.1 , and $67.4 \%$, respectively

or intestinal $\mathrm{BD}$ or in healthy controls. In addition, we confirmed that AIM was expressed in CD14- and CD16positive macrophages in intestinal tissue. AIM, a member of the scavenger receptor cysteine-rich superfamily, is initially identified as an apoptosis inhibitor that supports the survival of tissue macrophages against different types of pro-apoptotic stimuli $[28,29]$. We speculate that AIM, produced by resident macrophages in intestinal tissue, contributes to intestinal inflammation, and active macrophagederived AIM in the intestines results in elevated serum AIM levels.

Intestinal macrophages play important roles in local homeostasis and mucosal inflammation. Unique macrophages in normal colonic mucosa generally attenuate immune functions and induce protective immunity. As a result, intestinal macrophages contribute significantly to the pathogenesis of $\mathrm{CD}[5,6]$. Colonic macrophages show higher expression of CD14 and CD16 in patients with IBD than in healthy controls, indicating additional macrophage populations in the inflamed mucosa [5]. Infiltrating macrophages contribute to the initiation and sustention of the mucosal inflammation that is characteristic of human IBD. In addition, peripheral blood monocytes expressing CD16 were previously identified as a major proinflammatory cell population, producing cytokines such as tumor necrosis factor- $\alpha$ (TNF- $\alpha$ ), interleukin (IL)-1, and IL-12 [30, 31]. Koch et al. reported that CD16-positive peripheral blood 

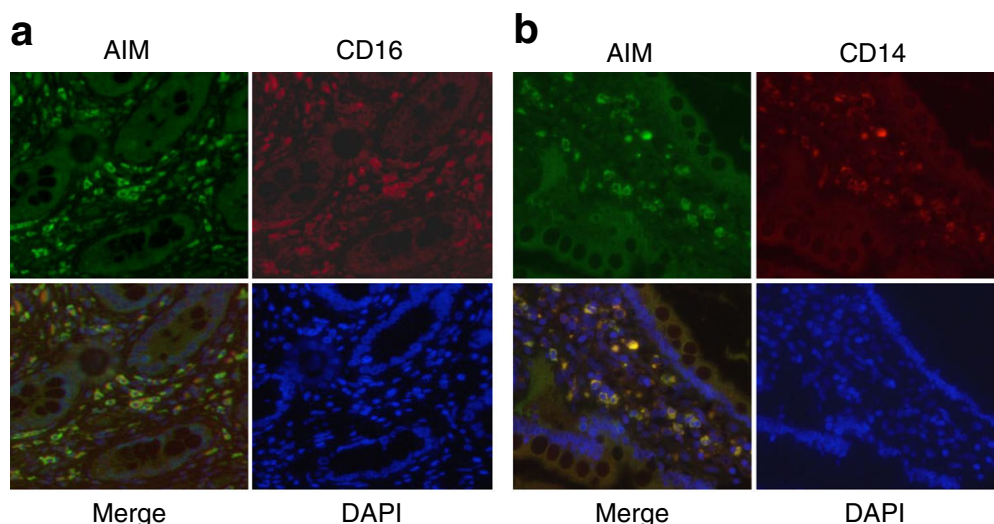

\section{C}
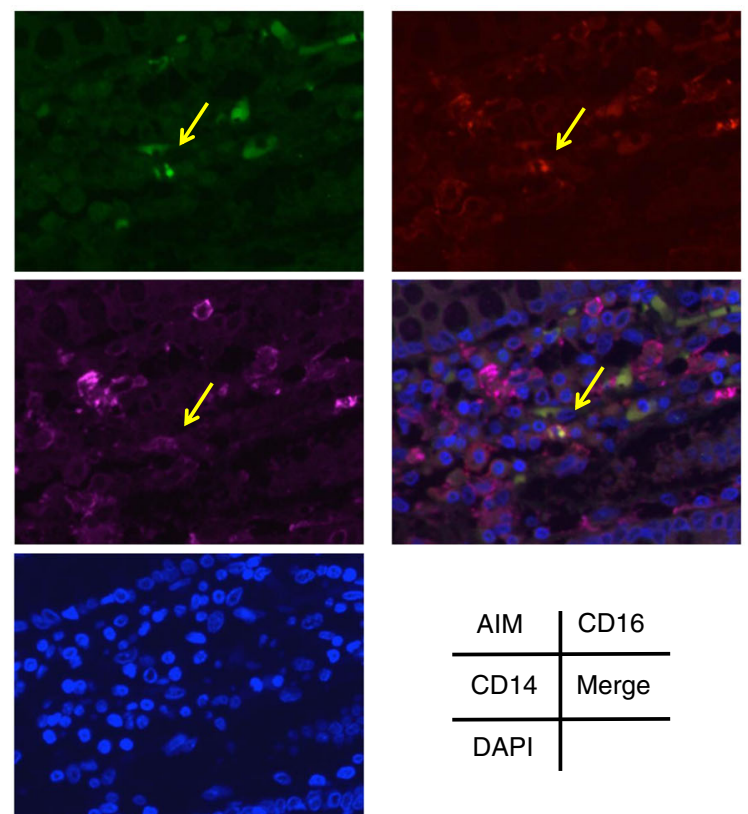

Fig. 6 Immunohistochemical staining of small intestine samples from patients with active CD. AIM expression is noted in submucosal mononuclear cells positive for CD14 (a) or CD16 (b). Some mononuclear cells were positive for CD14, CD16, and AlM antibodies (c; arrow). Microscopic magnification is $\times 400$

monocytes were significantly increased in active CD, particularly in patients with colonic involvement. Thus, CD14- and CD16-positive monocytes and macrophages, which are major contributors to the inflammatory infiltrate in the lamina propria, constitute a pivotal proinflammatory cell population in $\mathrm{CD}$ due to their production of large amounts of inflammatory cytokines such as IL-12, IL-23, and TNF- $\alpha$ [32-34].

Given the above, a significant reduction in peripheral CD14- and CD16-positive monocytes by leukocyte apheresis/adsorption and corticosteroids should improve intestinal inflammation [34, 35]. Azathioprine was also shown to inhibit the proliferation of CD16-positive cells in blood and lamina, resulting in the improvement of enterocolitis. In addition, infliximab has a reduced effect if there are no CD14-positive cells in the lamina propria.
These result show that AIM derived from CD14- or CD16-positive cells inhibits the apoptosis of intestinal macrophages by autocrine or paracrine mechanisms, and may thereby result in the sustentation of intestinal inflammation.

Recent clinical studies have reported high serum AIM levels in patients with liver fibrosis and chronic hepatitis $C$, [36] liver damage in patients with hepatocellular carcinoma, [37] and obesity-associated autoimmune disease in humans [38]. We confirmed that serum levels of AIM, which is actively secreted by active macrophage in the intestine, were found at higher levels in patients with $\mathrm{CD}$ than in patients with $\mathrm{UC}$ or intestinal $\mathrm{BD}$ or in healthy controls. Since AIM levels were high only in the patients with $\mathrm{CD}$ and not in those with UC or intestinal $\mathrm{BD}$, the evaluation of AIM levels may be helpful as an 
auxiliary method of discriminating between $C D$ and other chronic intestinal diseases. Although serum AIM levels were not associated with disease activity or clinical characteristics in CD, and there were no changes in AIM levels before and after treatment, increases of AIM are likely to be related to the pathogenesis of $\mathrm{CD}$, namely in the sustentation of inflammation due to the inhibition of macrophage apoptosis.

ASCA, a major serum marker, has been reported as a screening tool for $\mathrm{CD}$. In this study, ROC analysis showed that AIM had better sensitivity and specificity than ASCA for the screening of CD and intestinal inflammation disease. It is a well-known fact that ASCA is a less useful test in Asian than Caucasian populations [39]. It is possible that AIM can be used to screen for $\mathrm{CD}$ in patients from the Asian general population who have undiagnosed gastrointestinal symptoms.

The sequential assessments of AIM levels in the same $C D$ patients before and after treatment showed no changes in this study. While this analysis comprised only a small number of patients, serum AIM levels do not appear to be associated with disease activity in CD. However it is suggested that the upregulation of AIM may reflect the sustention of chronic inflammation in CD caused by the inhibition of apoptosis of active intestinal macrophages, and correlate with disease susceptibility in CD.

It has long been recognized that hypertrophied mesenteric adipose tissues surround the intestinal mesentery in CD [40]. Although TNF- $\alpha$ derived from these mesenteric adipose tissues induces intestinal inflammation, the cause and pathology of the CD-specific mesenteric adipose tissue accession have not been clearly elucidated. AIM is incorporated into adipocytes via CD36-mediated endocytosis, and subsequently induces lipolysis. Therefore it may play a role in inflammatory macrophage recruitment and induce TNF- $\alpha$ in mesenteric adipose tissues in CD [26-28, 41, 42]. AIM may influence the pathogenesis of $\mathrm{CD}$ not only by inhibiting the apoptosis of active intestinal macrophages, but also by enhancing the expression of TNF- $\alpha$ in these mesenteric adipose tissues.

There are several limitations to this study. First, it used a single-center design and enrolled a small number of patients. Therefore we should examine a larger sample in the near future. Second, AIM was expressed by active macrophages, although there was no association between serum AIM levels and CD activity. The inductive activity of AIM expression in macrophages is still unclear in the inflamed intestines of patients with $\mathrm{CD}$. We plan to investigate this issue by analyzing the function of the AIM gene using gene-modified mice, as there have been no reports of colitis mouse models in AIM knockout mice.

\section{Conclusions}

AIM is a novel biomarker of $\mathrm{CD}$ that can distinguish $\mathrm{CD}$ from UC or BD. It is suggested that AIM may contribute to intestinal inflammation by inhibiting the apoptosis of macrophages.

\begin{abstract}
Abbreviations
AIM: Apoptosis inhibitor of macrophages; ASCA: Anti-Saccharomyces cerevisiae antibodies; AUC: Area under the curve; BD: Behcet's disease; CAl: Clinical Activity Index; CD: Crohn's disease; CDAl: Crohn's Disease Activity Index; CRP: C-reactive protein; ELISA: Enzyme-linked immunosorbent assay; ESR: Erythrocyte sedimentation rate; IBD: Inflammatory bowel disease; IgG: Immunoglobulin G; IgM: Immunoglobulin M; IL: Interleukin; ROC: Receiver operating characteristics; ROC-AUC: Receiver operating characteristics area under the curve; SD: Standard deviation; TNF-a: Tumor necrosis factor-a; UC: Ulcerative colitis; WBC: White blood cell
\end{abstract}

\section{Acknowledgements}

We are grateful to Dr. Masatsugu Numata for giving helpful comment, and prepared in the design of the study.

\section{Funding}

This work did not receive any funding.

\section{Availability of data and materials}

The datasets used and/or analyzed during the current study are available from the corresponding author upon request.

\section{Authors' contributions}

Study design, data collection, supervision of patient selection, and manuscript preparation: YO, SK; data collection: KK, SA, FS, YN, SH, ST, HT; histologic evaluation of the intestinal samples: $\mathrm{YM}$; statistical analysis: $\mathrm{KO}$; supervision of patient selection and manuscript preparation: HU, HT, Al. All authors read and approved the final manuscript.

\section{Competing interests}

The authors have no financial or non-financial competing interests to declare.

\section{Consent for publication}

Not applicable.

\section{Ethics approval and consent to participate}

This study was performed in accordance with the Declaration of Helsinki and ethical guidelines for medical and health research involving human subjects, and approved by the clinical research ethics committee of Kagoshima University (number 27-178).

\section{Author details}

'Digestive and Lifestyle Diseases, Kagoshima University Graduate School of Medical and Dental Sciences, 8-35-1, Sakuragaoka, Kagoshima 890-8520, Japan. ${ }^{2}$ Center for Digestive and Liver Diseases, Miyazaki Medical Center Hospital, Miyazaki, Japan. ${ }^{3}$ Kagoshima City Hospital, Kagoshima, Japan.

Received: 10 December 2015 Accepted: 25 February 2017

Published online: 11 March 2017

\section{References}

1. Shivananda S, Lennard J, Logan R, Fear N, Price A, Carpenter L, et al. Incidence of inflammatory bowel disease across Europe: is there a difference between north and south? results of the European collaborative study on inflammatory bowel disease (EC-IBD). Gut. 1996:39:690-7.

2. Molodecky NA, Soon IS, Rabi DM, Ghali WA, Ferris M, Chemoff G, Benchimol E, Panaccione R, Ghosh S, Barkema HW, Kaplan GG. Increasing incidence and prevalence of the inflammatory bowel diseases with time, based on systematic review. Gastroenterology. 2012;142:46-54.

3. Huttenhower C, Kostic AD, Xavier RJ. Inflammatory bowel disease as a model for translating the microbiome. Immunity. 2014;40:843-54.

4. Kanai T, Watanabe M, Okazawa A, Nakamaru K, Okamoto M, Naganuma M, Ishii H, Ikeda M, Kurimoto M, Hibi T. Interleukin 18 is a potent proliferative 
factor for intestinal mucosal lymphocytes in Crohn's disease. Gastroenterology. 2000;1 19:1514-23.

5. Rogler G, Andus T, Aschenbrenner E, Vogl D, Falk W, Schölmerich J, Gross V. Alterations of the phenotype of colonic macrophages in inflammatory bowel disease. Eur J Gastroenterol Hepatol. 1997;9:893-9.

6. Schenk M, Mueller C. Adaptations of intestinal macrophages to an antigenrich environment. Semin Immunol. 2007;19:84-93.

7. Mowat C, Cole A, Windsor A, Ahmad T, Arnott I, Driscoll R, Mitton S, Orchard T, Rutter M, Younge L, Lees C, Ho GT, Satsangi J, Bloom S. Guidelines for the management of inflammatory bowel disease in adults. Gut. 2011;60:571-607.

8. Nikolaus S, Schreiber S. Diagnostics of inflammatory bowel disease. Gastroenterology. 2007;133:1670-89.

9. Al-Mohammad MA, Al-Ibrahim IA. Emerging inflammatory bowel disease in Saudi outpatients: a report of 693 cases. Saudi J Gastroenterol. 2013;19:16-22.

10. Annese V, Daperno M, Rutter MD, Amiot A, Bossuyt P, East J, Ferrante M, Gotz M, Katsanos KH, Kieblich R, Odras I, Repici A, Rosa B, Sebastian S, Kucharzik T, Eliakim R. European evidence based consensus for endoscopy in inflammatory bowel disease. J Crohn's Colitis. 2013;7:982-1018.

11. Rutgeerts $\mathrm{P}$, Vermeire $\mathrm{S}$. Serological diagnosis of inflammatory bowel disease. Lancet. 2000;356:2117-8.

12. Gabay C, Kushner I. Acute-phase proteins and other systemic responses to inflammation. N Engl J Med. 1999;340:448-54.

13. Saverymuttu SH, Hodgson HJ, Chadwick VS, Pepys MB. Differing acute phase responses in Crohn's disease and ulcerative colitis. Gut. 1986;27:809-13.

14. Sachar DB, Smith H, Chan S, Cohen LB, Lichtiger S, Messer J. Erythrocytic sedimentation rate as a measure of clinical activity in inflammatory bowel disease. J Clin Gastroenterol. 1986;8:647-50.

15. Costa F, Mumolo MG, Ceccarelli L, Bellini M, Romano MR, Sterpi C, Ricchiuti A Marchi S, Bottai M. Calprotectin is a stronger marker of relapse in ulcerative colitis than in Crohn's disease. Gut. 2005;54:364-8.

16. Vermeire $S$, Van Assche G, Rutgeerts P. Laboratory markers in IBD: useful, magic, or unnecessary toys? Gut. 2006;55:426-31.

17. Beaven SW, Abreu MT. Biomarkers in inflammatory bowel disease. Curr Opin Gastroenterol. 2004:20:318-27.

18. Sandborn WJ. Serologic markers in inflammatory bowel disease: state of the art. Rev Gastroenterol Disord. 2004:4:167-74.

19. Targan SR, Karp LC. Serology and laboratory markers of disease activity. In: Sartor RB, Sandborn WJ, editors. Kirsner's inflammatory bowel disease. 6th ed. New York: Saunders; 2004. p. 442-52.

20. Kanmura S, Uto H, Numata M, Hashimoto S, Moriuchi A, Fuijta H, Oketani M, Ido A, Kodama M, Ohi H, Tsubouchi H. Human neutrophil peptides 1-3 are useful biomarkers in patients with active ulcerative colitis. Inflamm Bowel Dis. 2009;15:909-17.

21. Quinton JF, Sendid B, Reumaux D, Duthilleul P, Cortot A, Grandbastien B, Charrier G, Targan SR, Colombel JF, Poulain D. Anti-Saccaromyces cerevisiae mannan antibodies combined with antineutrophil cytoplasmic antoantibodies in inflammatory bowel disease : prevalence and diagnostic role. Gut. 1998;42:788-91.

22. Hisabe T, Matsui T, Sakurai T, Murakami Y, Tanabe H, Matake H, Yao T, Kamachi S, Iwashita A. Anti-Saccharomyces cerevisiae antibodies in Japanese patients with inflammatory bowel disease: diagnostic accuracy and clinical value. J Gastroenterol. 2003;38:121-6.

23. Kim BC, Park S, Han J, Kim JH, Kim TI, Kim WH. Clinical significance of antiSaccharomyces cerevisiae antibody (ASCA) in Korean patients with Crohn's disease and its relationship to the disease clinical course. Dig Liver Dis. 2007:39:610-6

24. Matsui T, Yao T, Sakurai T, Yao K, Hirai F, Matake H, Tsuda S, Wada Y, Iwashita A, Kamachi S. Clinical features and pattern of indeterminate colitis: Crohn's disease with ulcerative colitis-like clinical presentation. J Gastroenterol. 2003;38:647-55.

25. Miyazaki T, Hirokami Y, Matsuhashi N, Takatsuka H, Nito M. Increased susceptibility of thymocytes to apoptosis in mice lacking AIM, a novel murine macrophage-derived soluble factor belonging to the scavenger receptor cysteine-rich domain superfamily. J Exp Med. 1999;189:413-22.

26. Kurokawa J, Nagano H, Ohara O, Kubota N, Kadowaki T, Arai S, Miyazaki T. Apoptosis inhibitor of macrophage (AIM) is required for obesity-associated recruitment of inflammatory macrophages into adipose tissue. Proc Natl Acad Sci U S A. 2011;108:12072-7.

27. Arai S, Miyazaki T. Impacts of the apoptosis inhibitor of macrophage (AIM) on obesity-associated inflammatory disease. Smin Immnopathol. 2014;36:3-12.

28. Iwamura Y, Mori M, Nakashima K, Mikami T, Murayama K, Arai S, Miyazaki T. Apoptosis inhibitor of macrophage (AIM) diminishes lipid droplet-coating proteins leading to lipolysis in adipocytes. Biochem Biophys Res Commun. 2012:422:476-81.

29. Haruta I, Kato Y, Hashimoto E, Minjares C, Kennedy S, Uto H, Yamauchi K, Kobayashi M, Yusa S, Muller U, Hayashi N, Miyazaki T. Association of AlM, a novel apoptosis inhibitory factor, with hepatitis via supporting macrophage survival and enhancing phagocytotic function of macrophages. J Biol Chem. 2001;276:22910-4.

30. Ziegler-Heitbrock L. The CD14+ CD16+ blood monocytes: their role in infection and inflammation. J Leukoc Biol. 2007:81:584-92.

31. Hanai $H$, lida T, Takeuchi $K$, Watanabe F, Yamada M, Kikuyama M. Adsorptive depletion of elevated proinflammatory CD14 + CD16 + DR++ monocytes in patients with inflammatory bowel disease. Am J Gastroenterol. 2008;103:1210-6.

32. Kamada N, Hisamatsu T, Okamoto S, Chinen H, Kobayashi T, Sato T, Sakuraba A, Kitazume MT, Sugita A, Koganei K, Akagawa KS, Hibi T. Unique CD14 intestinal macrophages contribute to the pathogenesis of Crohn disease via IL-23/IFN-gamma axis. J Clin Invest. 2008;118:2269-80.

33. Koch S, Kucharzik T, Heidemann J, Nusrat A, Luegering A. Investigating the role of proinflammatory CD16+ monocytes in the pathogenesis of inflammatory bowel disease. Clin Exp Immunol. 2010;161:332-41.

34. Hanai H, lida T, Takeuchi K, Watanabe F, Yamada M, Kikuyama M, Maruyama Y, Iwaoka Y, Hirayama K, Nagata S, Takai K. Adsorptive depletion of elevated proinflammatory CD14 + CD16 + DR++ monocytes in patients with inflammatory bowel disease. Am J Gastroenterol. 2008;103:1210-6.

35. Kanai T, Makita S, Kawamura T, Nemoto Y, Kubota D, Nagayama K Extracorporeal elimination of TNF-alpha-producing CD14 (dull) CD16 (+) monocytes in leukocytapheresis therapy for ulcerative colitis. Inflamm Bowel Dis. 2007;13:284-90

36. Mera K, Uto H, Mawatari S, Ido A, Yoshimine Y, Nosaki T, Oda K, Tabu K, Kumagai K, Tamai T, Moriuchi A, Oketani M, Shimada Y, Hidaka M, Eguchi S, Tsubouchi H. Serum levels of apoptosis inhibitor of macrophage are associated with hepatic fibrosis in patients with chronic hepatitis C. BMC Gastroenterol. 2014;14:27.

37. Yamazaki T, Mori M, Arai S, Tateishi R, Abe M, Ban M, Nishijima A, Maeda M, Asano T, Kai T, Izumino K, Takahashi J, Aoyama K, Harada S, Takebayashi T, Gunji T, Ohnishi S, Seto S, Yoshida Y, Hiasa Y, Koike K, Yamamura K, Inoue K, Miyazaki T. Circulating AIM as an indicator of liver damage and hepatocellular carcinoma in humans. Plos one. 2014:9:e109123.

38. Arai S, Maehara N, Iwamura Y, Honda S, Nakashima K, Kai T, Ogishi M, Morita K, Kurokawa J, Mori M, Motoi Y, Miyake K, Matsuhashi N, Yamamura K, Ohara O, Shibuya A, Wakeland EK, Li QZ, Miyazaki T. Obesity-associated autoantibody production requires AIM to retain the immunoglobulin M immune complex on follicular dendritic cells. Cell Rep. 2013;3:1187-98.

39. Saito H, Fukuda Y, Katsuragi K, Tanaka M, Satomi M, Shimoyama T, Saito T, Tachikawa T. Isolation of peptides useful for differential diagnosis of Crohn's disease and ulcerative colitis. Gut. 2003;52:535-40.

40. Sheehan AL, Warren BF, Gear MW, Shepherd NA. Fat-wrapping in Crohn's disease: pathological basis and relevance to surgical practice. Br J Surg. 1992;79:955-8

41. Kredel LI, Siegmund B. Adipose-tissue and intestinal inflammation - visceral obesity and creeping fat. Front Immunol. 2014:5:462.

42. Fink C, Karagiannides I, Bakirtzi K, Pothoulakis C. Adipose tissue and inflammatory bowel disease pathogenesis. Inflamm Bowel Dis. 2012;18:1550-7.

\section{Submit your next manuscript to BioMed Central and we will help you at every step:}

- We accept pre-submission inquiries

- Our selector tool helps you to find the most relevant journal

- We provide round the clock customer support

- Convenient online submission

- Thorough peer review

- Inclusion in PubMed and all major indexing services

- Maximum visibility for your research

Submit your manuscript at www.biomedcentral.com/submit 